http://jmscr.igmpublication.org/home/ ISSN (e)-2347-176x ISSN (p) 2455-0450

crossref DOI: https://dx.doi.org/10.18535/jmscr/v7i11.63

Journal Of Medical Science And Clinical Research

IGM Publication

An Official Publication of IGM Publication

\title{
Does the anatomical location, size of tympanic membrane perforation effects the degree and frequencies of hearing loss?
}

\author{
Authors \\ Satish Kumar Bandaru ${ }^{1}$, Phani Bhushan Ivaturi ${ }^{*}$, Nirupama. ${ }^{3}$ \\ ${ }^{1}$ Senior Resident, Department of ENT, Andhra Medical College, Visakhapatnam \\ ${ }^{2}$ Assistant Professor, Department of ENT, Government Medical College, Nalgonda \\ ${ }^{3}$ Post Graduate, Department of ENT, Andhra Medical College \\ *Corresponding Author \\ Phani Bhushan Ivaturi
}

\begin{abstract}
Background: The large effective surface area of an intact and normally vibrating tympanic membrane plays a major role in middle ear transformer mechanism. Perforation of tympanic membrane can lead to varying degrees of hearing loss. Therefore accurate assessment of the perforation of tympanic membrane and its relationship with hearing loss is important for the clinician.

Methods: A prospective study was done on Patients attending the outpatient department in Tertiary care centre, Vizag during October 2016 to October 2018 who had a perforation in tympanic membrane. A sample size of 100 perforated ears from patients of safe CSOM were included in the study. Photographs of the perforated tympanic membrane were taken using otoendoscope. The site of perforation was noted anterior or posterior to handle of malleus. The images were analysed using 'IMAGE $J$ ' software, a free download software available on the internet. The size of the perforation and the total size of the tympanic membrane were measured in terms of pixels. The ratio of area of the perforation $(P)$ to the area of the tympanic membrane $(Q)$ was calculated as percentage using the formula $P / Q \times 100$

Results: The most commonly affected age group is between 20 to 35 years. The tubotympanic type of chronic otitis media is more common in females. Chronic otitis media is more common in low socioeconomic group due to lack of advanced medical care especially in rural areas. The present study showed a significant linear association between the degree of hearing loss and size of perforation of tympanic membrane, with $p$ value 0.002.

Conclusion: The magnitude of hearing loss increased with increase in size of the perforation of tympanic membrane.There was no significant relationship between location of tympanic membrane perforation and degree of hearing loss.

Keywords: Transformer mechanism, Image J, Tubotympanic disease, Otoendoscope.
\end{abstract}

\section{Introduction}

Tympanic membrane is a membranous partition separating external auditory canal from the middle ear, measuring $8-9 \mathrm{~mm}$ horizontally and $9-10 \mathrm{~mm}$ vertically. The large effective surface area of an intact and normally vibrating tympanic membrane plays a major role in middle ear transformer mechanism ${ }^{1}$. Perforation of tympanic membrane is caused by wide variety of causes, the most common being infections and trauma. Infections 
(acute otitis media, chronic otitis media, tuberculosis), trauma (barotrauma, temporal bone fracture), iatrogenic (ventilation tubes). Perforation of tympanic membrane leads to varying degree of conductive hearing loss ${ }^{2}$.

Hearing loss is a national health problem with significant physical and psychosocial problem. So it is important to diagnose and treat perforation of tympanic membrane as early as possible as untreated perforation leads to ongoing destructive changes in the middle ear, thus adding to further hearing loss ${ }^{3}$. Therefore accurate assessment of the perforation of tympanic membrane and its relationship with hearing loss is important as it enables the clinician to optimally assess the condition and offer an appropriate solution. And also, the incidence of otitis media and tympanic membrane perforation is high in developing countries like India especially in the rural area, so the study has been undertaken.

\section{Aims \& Objectives of the Study}

1) To study the various sites and size of perforation in patients of safe chronic otitis media.

2) To correlate the size and site of the tympanic membrane perforation with pure tone audiogram.

\section{Materials and Methods}

A prospective study was done on Patients attending the outpatient department in a Tertiary Care Hospital, Vizag in the study period from July 2018 to July 2019 who had a perforation in tympanic membrane. A sample size of 100 perforated ears from patients of safe CSOM were included in the study.

\section{Inclusion Criteria}

1) Subjects with central perforation of tympanic membrane due to chronic otitis media (tubotymapnic disease).

2) Subjects with no history of ear discharge for atleast 6weeks - totally dry perforation.

3) Subjects with ossicular chain continuity as confirmed by patch test.
4) Subjects aged between 20 to 55 years.

\section{Exclusion Criteria}

1) Patients with active chronic otitis media.

2) Patients with attico-antral disease - unsafe CSOM.

3) Patients with ossicular chain disruption / fixation

4) Patients with inconsistent response on pure tone audiogram.

5) Patients with mixed or sensory neural hearing loss.

6) Patients with traumatic perforation.

A written informed consent was taken from the patients who were included in the study. Photographs of the perforated tympanic membrane were taken using otoendoscope. The site of perforation was noted anterior or posterior to handle of malleus. The images were analysed using 'IMAGE J' software, free download software available on the internet. The size of the perforation and the total size of the tympanic membrane were measured in terms of pixels. The ratio of area of the perforation $(\mathrm{P})$ to the area of the tympanic membrane $(\mathrm{Q})$ was calculated as percentage using the formula $\mathrm{P} / \mathrm{Q} \times 100$

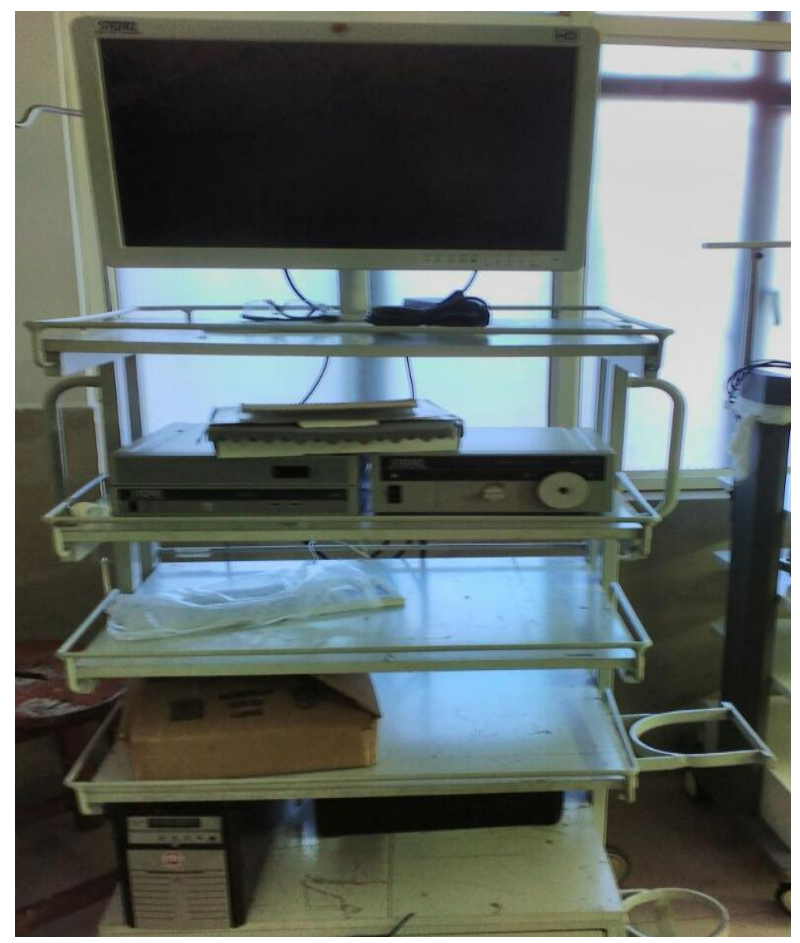

Figure: 1 Storz Endoscopic Monitor Set Up 


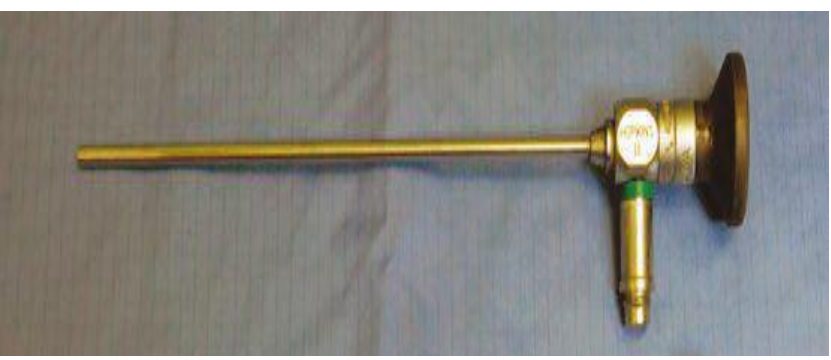

Figure: 2 Storz 0 Degree Endoscope

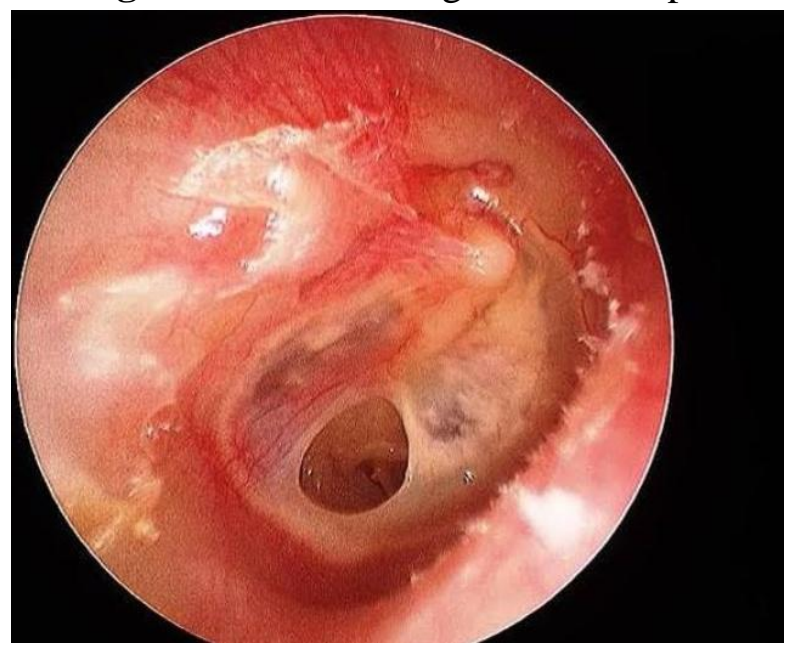

Figure 3: Image of Tympanic Membrane Perforation

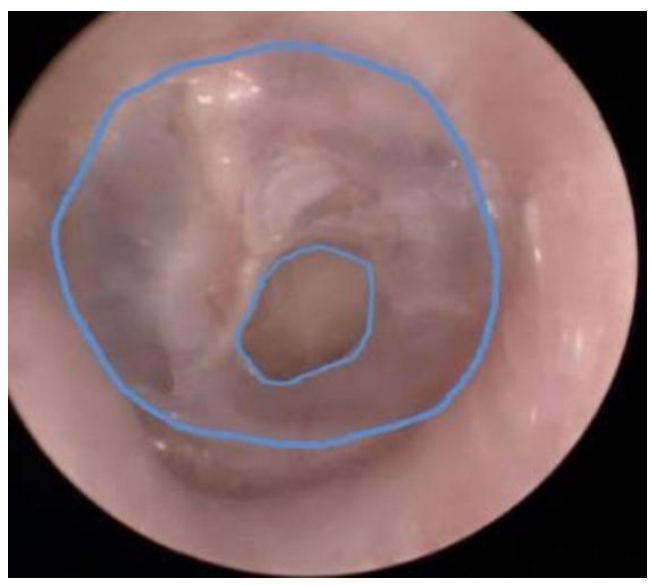

Figure 4: Image Showing the Calculation of Size of Tympanic Membrane Perforation
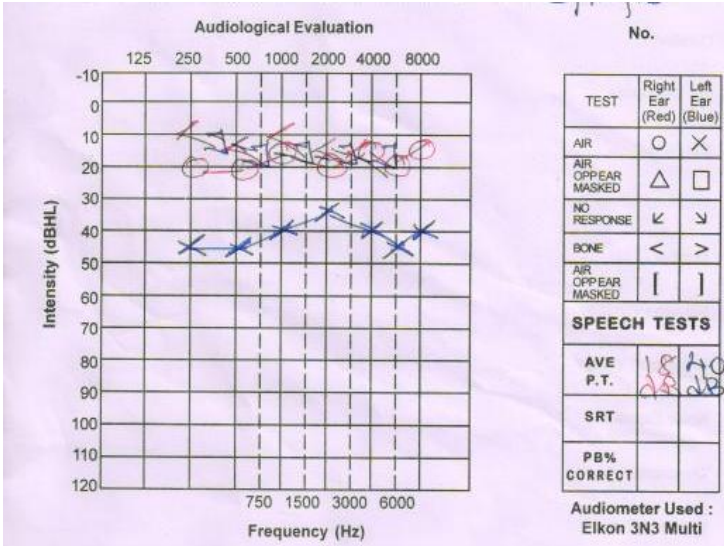

Figure 5: Image Showing the PTA

\section{About the software}

Image $\mathbf{J}$ is a public domain java image processing program inspired by NIH image for the Macintosh. It runs on any computer with a java 1.1 or later virtual machine, either as an online applet or a downloadable application.

The author, Wayne Rasband (wayne@codon.nih.gov), is at research services branch, National Institute of Mental Health, Bethesda, Maryland, USA.

The best source of information about Image $\mathrm{J}$ can be found at the Image $\mathbf{J}$ homepage (http://rsb.info.nih.gov/ij/).

The data was presented as mean \pm standard deviation (SD). Kruskal-Wallis ANOVA was used for multiple group comparisions. For correlation, spearman's correlation co-effecient was used. Statistical analysis was performed using IBM SPSS statistics version 20 for windows. A ' $p$ ' value of 0.05 or less was considered significant.

\section{Results}

1. Age and sex distribution of the study population

A total of 100 ears were included. It included 46 males of whom had 10 bilateral perforations and 54 females of whom 6 had bilateral perforation (Fig 10). The mean age of the patient in the study group was 32.5 years i.e, predominantly middle aged population.

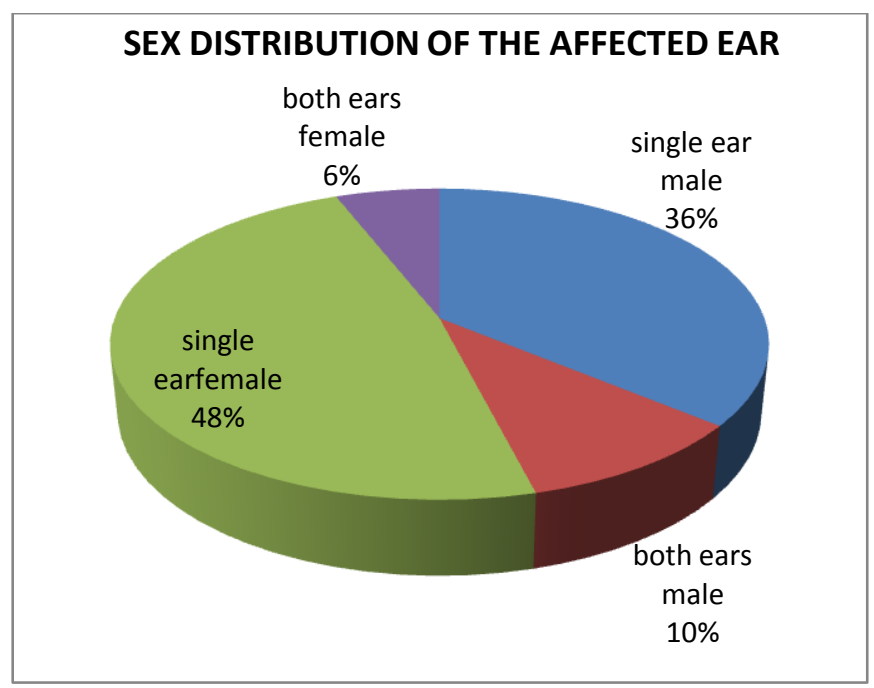

Figure 6: Sex Distribution of Affected Ears 
2. Average hearing loss due to tympanic membrane perforation at each frequency

When a simple average of the hearing loss at each frequency was calculated, it was seen that there was a higher average hearing loss at low frequency and it decreased as the frequency increased (Fig 7).

\section{Average thresholds at each frequency}

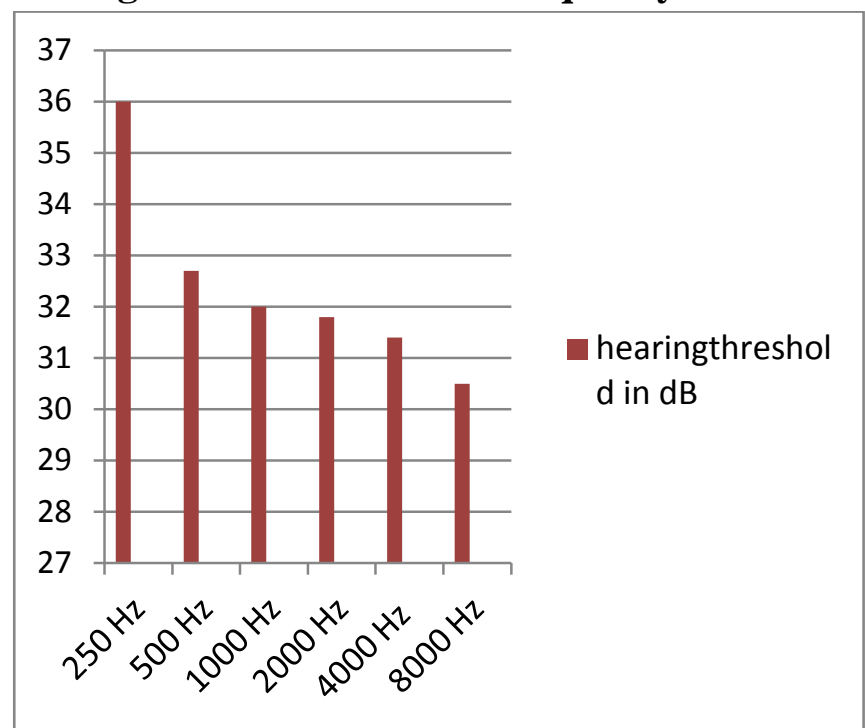

Figure 7: Average hearing loss at individual frequencies due to tympanic membrane perforation.

\section{Size of the tympanic membrane perforation and average hearing loss}

The average hearing loss increased with the size of the perforation. Size was measured as a percentage of TM area involved by the perforation and pure tone average is the average hearing thresholds at 500, 1000 and $2000 \mathrm{~Hz}$. Spearman's correlation co efficient was used. The spearman's $\sigma$ value +0.42 at a $P$ value of 0.002 and found to be significant at $99 \%$ confidence intervals.

Table 1: Size of the perforation and pure tone average- comparison among four groups

\begin{tabular}{|l|c|c|}
\hline $\begin{array}{l}\text { Size of } \\
\text { perforation }(\%)\end{array}$ & $\begin{array}{c}\text { Number of } \\
\text { cases }\end{array}$ & $\begin{array}{l}\text { Hearing } \\
\text { loss }(\mathbf{d B})\end{array}$ \\
\hline$<10$ & 24 & $27.0 \pm 8$ \\
\hline $11-20$ & 24 & $33.3 \pm 6.3$ \\
\hline $21-30$ & 34 & $34.6 \pm 6$ \\
\hline 31 and above & 18 & $39.3 \pm 4.4$ \\
\hline Total & 100 & $33.2 \pm 7.3$ \\
\hline
\end{tabular}

Kruskal-Wallis ANOVAH $=11.39 \mathrm{P}$ value $=0.002(\mathrm{p}<0.05$, significant)

\section{Pure tone average and site of perforation} The below illustrates the association between the site of tympanic membrane perforation and hearing loss (Table ). The cases were divided into three groups i.e., ears with perforation involving only the anterior quadrant, those involving only the posterior quadrant and those involving both quadrants. Kruskal Wallis ANOVA was used to test for a statistically significant association between the groups with respect to pure tone average and there was found to be none. Though there was a higher average loss in posterior only perforation in comparison to anterior only perforations, this was not found to be statistically significant (Fig)

Table 2: Association between pure tone average and site of perforation

\begin{tabular}{|l|c|c|}
\hline Site of perforation & $\begin{array}{c}\text { Number of } \\
\text { cases }\end{array}$ & $\begin{array}{c}\text { Pure tone } \\
\text { average }\end{array}$ \\
\hline Anterior & 50 & $32.1 \pm 8.8$ \\
\hline Posterior & 08 & $35.5 \pm 4.7$ \\
\hline $\begin{array}{l}\text { Anterior } \\
\text { +Posterior }\end{array}$ & 42 & $36.4 \pm 7.9$ \\
\hline Total & 100 & $34.2 \pm 8.5$ \\
\hline
\end{tabular}

K-W ANOVA, H=4.09 P=0.31 Not Significant

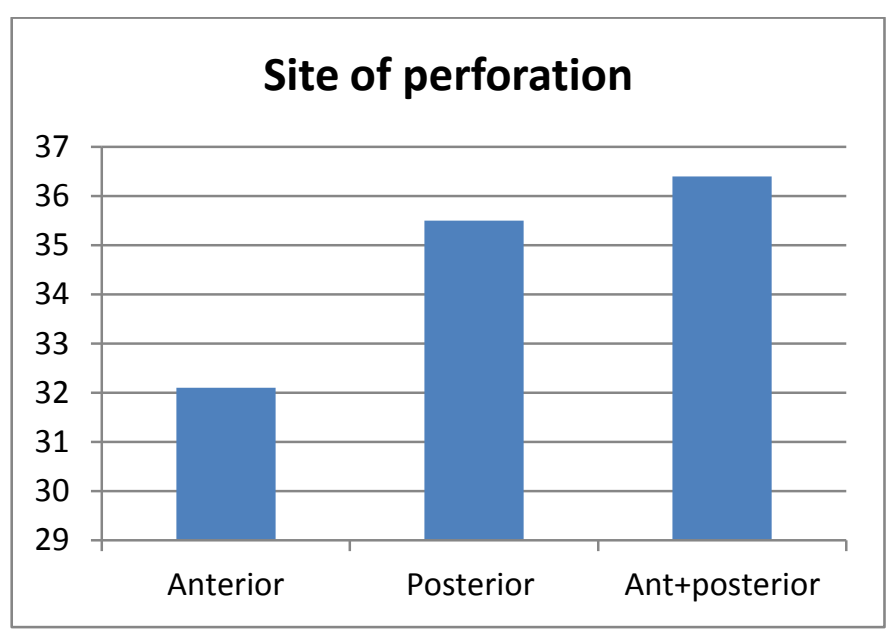

Figure 8: Relationship between pure tone average and site of perforation

\section{Discussion}

Perforation of tympanic membrane is a common otological problem. It leads to varying degree of conductive hearing loss. The study attempts to correlate the size and site of tympanic membrane perforations with pure tone audiometry. 
The present study was conducted in 100 patients in the outpatient department of ENT. Methodology was similar to that used in Ibekwe TS et $\mathrm{al}^{4}$ study. After taking detailed history and a clinical examination, video otoscopy of all ears was done with a Welch-Allyn compact video otoscope system and images were recorded in a computer. Area of perforation $(\mathrm{P})$ and area of entire tympanic membrane $(\mathrm{Q})$ were calculated and percentage of area of perforation $(\mathrm{P} / \mathrm{Q} \times 100)$ for every ear was obtained by using IMAGE J software. Matsuda $\mathrm{Y}$ et $\mathrm{al}^{5}$ have also used image analysis equipment (WIN ROOF version 5.5 software, mitani corporation, Tokyo, Japan) to study the effect of perforation of tympanic membrane on middle ear transmission.

Sood AS et $\mathrm{al}^{6}$ measured size of perforation by placing $1 \mathrm{~mm}$ thin wire loop over perforation and adjusted according to size and shape of perforation. After that two maximum diameters were measured from wire loop by vernier callipers.

Kumar Ajith $\mathrm{U}^{7}$ used a graduated right angled fine aural probe with an operating microscope to measure the size of perforation in their study.

Hsu CY et $\mathrm{al}^{8}$ used a computer program which was designed by them. In their study, they concluded that size of perforation calculation using computer program and visual estimation showed a larger differences. The variations were large for different individuals even experienced otologists.

In our study the most common affected age group was 20-35 years. People of this age group are more concerned about their health. In our study, females are more than males. Most of the cases were due to chronic otitis media. Therefore we conclude that chronic otitis media is the most common cause of perforation of tympanic membrane. Most common symptoms were hearing loss and discharge. Pure tone audiogram was done for all patients. We had done patch test for ears having hearing loss more than 30decibel to rule out any ossicular discontinuity. Kumar Ajith $\mathrm{U}^{7}$ and Bhat VK have done patch test, similar to our study to exclude the ears with ossicular pathology.

Bhusal et al ${ }^{9}$ measured the diameter of perforation and classified perforation into categories based on the area of tympanic membrane affected by perforation.

\section{Relation of Size of Perforation and Hearing Loss}

Our study showed a significant linear association between the degree of hearing loss and size of perforation of tympanic membrane, with $\mathrm{p}$ value 0.002 . As the ' $p$ ' value is less than 0.05 it implies that the average hearing loss increased with increase in size of perforation. It was also stated that hearing loss due to perforation was more at low frequencies than at high frequencies.

Table: 3 showing ' $p$ ' value of size of perforation in relation to hearing loss in various studies.

\begin{tabular}{|c|c|c|}
\hline Author & $\begin{array}{c}\text { Size of perforation } \\
\text { and hearing loss ' } \mathbf{p} \text { ' } \\
\text { value }\end{array}$ & Significance \\
\hline Sood AS et al & 0.000 & Significant \\
\hline Ediale J et al & 0.000 & Significant \\
\hline Herkal K et al & $<0.001$ & Significant \\
\hline Pannu KK et al & $<0.001$ & Significant \\
\hline Present study & 0.002 & Significant \\
\hline
\end{tabular}

Johnson Ediale et al ${ }^{2}$ in 2018 conducted a study on 148 patients, in which he proved the severity of hearing loss increased with an increase in size of perforation of tympanic membrane. Similar results were obtained in study done by Sood As et $\mathrm{al}^{7}$, Maharajan et al ${ }^{10}$.They found that patients with subtotal, total perforations showed larger air-bone gap with more hearing loss. Size of the perforation is the most important determinant of hearing loss, was also proved by Pannu et al ${ }^{1}$ and Nepal et $\mathrm{al}^{11}$.Ribeiro FA et $\mathrm{al}^{12}$, in their study showed no significant relationship between hearing loss and size of perforation of tympanic membrane. Matsuda $\mathrm{Y}$ et $\mathrm{al}^{5}$ in their study stated that conuction disturbance in the low frequency range increases due to inflammatory changes in middle ear. In such cases, due to tympanosclerosis or sclerotic changes of the ossicles tympanic compliance may decrease which leads to conduction disturbance in low frequency range. 
Even in cases of traumatic perforation of the tympanic membrane it is difficult to determine whether the observed conduction disturbance is only due to perforation.

\section{Site of Perforation with Hearing Loss}

The present study showed no significant difference in the magnitude of hearing loss based on site of perforation of tympanic membrane.

In our study we found 50 cases of anterior quadrant perforation, 8 cases of posterior quadrant perforation and 42 cases of both posterior and anterior quadrant perforation. ' $\mathrm{p}$ ' value was found to be 0.32 which is not significant. It implies that there is no significant relationship between site of perforation and degree of hearing loss.

Similar results were also shown by Sood As et al ${ }^{6}$ and Ibekwe TS et $\mathrm{al}^{4}$ who showed no relation between location of perforation and magnitude of hearing loss.

Maharajan et al ${ }^{10}$ and Berger et al ${ }^{13}$ showed statistically significant relation between site of perforation and magnitude of hearing loss, which is maximum for posterior quadrant perforation.

This can be explained on the basis that posterior or posterior-inferior quadrant perforations expose the round window directly to sound waves, then the sound would travel to both windows at the same time and cancel each other. This is known as BAFFLE EFFECT, where hearing loss is out of proportion to the size of perforation.

Ediale $\mathrm{J}$ et $\mathrm{al}^{2}$ in their study showed that site of perforation influences the hearing loss. The ' $p$ ' value observed in relation to site of perforation and hearing loss was 0.004 . As the ' $p$ ' value is less than 0.05 it is significant. But in our study the ' $p$ ' value is not significant.

Table: 4 showing 'p' value of site of perforation in relation to hearing loss in various studies.

\begin{tabular}{|c|c|c|}
\hline Author & $\begin{array}{c}\text { Site of perforation } \\
\text { and hearing loss ' } \mathbf{p} \text { ' } \\
\text { value }\end{array}$ & Significance \\
\hline Sood As et al. & 0.689 & not significant \\
\hline Maharajan et al. & 0.000 & Significant \\
\hline Ediale J et al. & 0.004 & Significant \\
\hline Herlak K et al. & 0.327 & Not significant \\
\hline Present study & 0.31 & Not significant \\
\hline
\end{tabular}

Kumar UA et $\mathrm{al}^{7}$. In their study found that site of perforation does not depend upon degree of hearing loss except in the anteriosuperior quadrant. Anthony and Harrison ${ }^{14}$ in their study showed that posterioinferior quadrant perforation caused more hearing loss than anterioinferior perforation at $250 \mathrm{~Hz}$, equal loss at $4000 \mathrm{~Hz}$ and lesser loss at intermediate frequencies. Based on the above studies, there is no consensus on the site of perforation and its relation on hearing loss. This requires further study. Our study includes only 8 patients with purely posterior quadrant perforation, which is not sufficient to arrive at a conclusion.

\section{Conclusion}

Chronic otitis media is the chronic inflammation of the muco-periosteal lining of the middle ear cleft with hearing impairment.

Chronic otitis media is the most common otological problem encountered in developing countries due to poor nutrition, poor socioeconomic status, lack of health education and poor hygiene habits. It is one of the major causes of deafness in India.

\section{In the present study following observations are made}

1. The most commonly affected age group is between 20 to 35 years.

2. The tubotympanic type of chronic otitis media is more common in females.

3. Chronic otitis media is more common in low socioeconomic group due to lack of advanced medical care especially in rural areas.

\section{The following conclusions are made from the present study}

1) The magnitude of hearing loss increased with increase in size of the perforation of tympanic membrane.

2) The degree of hearing loss is dependent on frequency, which was more at lower frequencies than at higher frequencies. 
3) The size of tympanic membrane perforation showed a high positive correlation with hearing loss at lower frequencies.

4) There was no significant relationship between location of tympanic membrane perforation and degree of hearing loss.

5) Site of perforation does not have any effect on frequency of hearing loss.

\section{References}

1. Kulwant Kaur Pannu, Snyachadha, Dinesh Kumar, Preeti. Evaluation of hearing loss in tympanic membrane perforation. Indian J Otolaryngol Head Neck Surg. 2011;63(3): 208-213.

2. Ediale J, Adobamen PROC, Ibekwe TS. Audiometric assessment of adolscents and adults with tympanic membrane perforation in Benin city. Int. J Otorhinolaryngol Head Neck Surg 2018; 4 : 901-6.

3. Alsarhan HW, Dawood MR , Jwery AK , Khammas AH, Hamad AK. Assessment of hearing loss in tympanic membrane perforation. Adv Arab Acad AudioVestibul J 2016; 3: 16-9.

4. Ibekwe TS, Nwaorgu OG, Adeosun AA, Kokong DD, Lawal HO, et al. Assessments of the size of tympanic membrane perforations: a comparision of clinical estimations with video-otoscopic calculations. Ear Nose Throat J .2008; 87(10):567-9.

5. Matsuda Y, Kurita T. Ueda Y, Ito S, Nakashima T. Effect of tympanic membrane perforation on mile ear sound transmission. J Laryngol Otol. 2009; 123;31:81-89.

6. Sood AS, Pal P, Kumar A. Tympanic membrane perforation: correlation of hearing loss with its site and size. Int $\mathbf{J}$ Otorhinolaryngol Head Neck Surg 2018; 4 : 397-402.
7. Kumar UA, Bhat KV. Do the site and size of tympanic membrane perforation correlate with audiogram ? Asian journal of Ear, Nose and Throat 2007;4: 25-30

8. Hsu CY, Chen YS, Hwang. A computer programme to calculate the size of tympanic membrane perforations. Clin Otolaryngol All Sc 2004, 29:340-342.

9. Bhusal CL, Guragain RPS,Shrivastav RP. Size of tympanic membrane perforation and hearing loss. J Nep Med Assoc 2006;45:167-72

10. Maharajan M , Kafle P, Bista M , Shrestha $\mathrm{S}, \mathrm{KC}$ Toran. Observation of hearing loss in patients with chronic suppurative otitis media tubotympanic type. Kathmandu University Medical Journal. 2009;7(4): 397-401

11. Nepal A, Bhandary S, Mishra SC, Singh I, Kumar P. The morphology of central tympanic membrane perforations. Nepal Med Coll J. 2007;9(4):239-44.

12. Reberio FA, Gaudino VR, Pinheiro CD, Marcal GJ, Mitre EI. Objective comparision between perforation and hearing loss. Braz J Otorhinolaryngol. 2014;80:386.

13. Berger G. Nature of spontaneous tympanic membrane perforation in acute otitis media in children. J Laryngol Otol. 1989;103 (12):1150-3.

14. Anthony WP, Harrison CW. Tympanic membrane perforation. Arch Otolaryngol 1972;95:504-510. 